This item was submitted to Loughborough's Research Repository by the author.

Items in Figshare are protected by copyright, with all rights reserved, unless otherwise indicated.

\title{
A new vision for the automation systems engineering for automotive powertrain assembly
}

PLEASE CITE THE PUBLISHED VERSION

http://dx.doi.org/10.1080/09511921003596780

PUBLISHER

(c) Taylor \& Francis

VERSION

AM (Accepted Manuscript)

LICENCE

CC BY-NC-ND 4.0

\section{REPOSITORY RECORD}

Haq, Izhar UI, Radmehr P. Monfared, Robert Harrison, Leslie J. Lee, and Andrew A. West. 2019. "A New Vision for the Automation Systems Engineering for Automotive Powertrain Assembly". figshare. https://hdl.handle.net/2134/13391. 
This item was submitted to Loughborough's Institutional Repository (https://dspace.lboro.ac.uk/) by the author and is made available under the following Creative Commons Licence conditions.

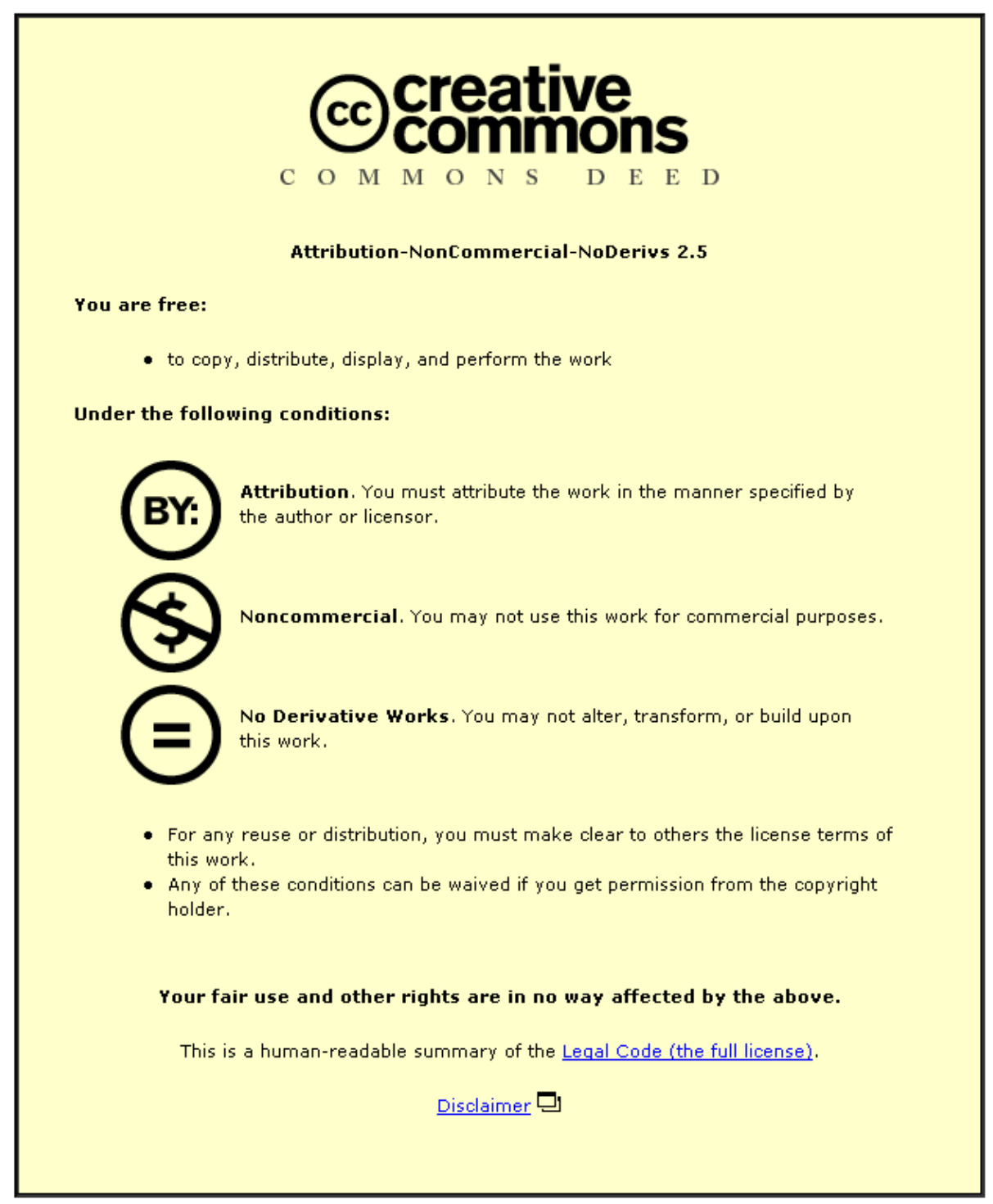

For the full text of this licence, please go to: http://creativecommons.org/licenses/by-nc-nd/2.5/ 


\title{
A new vision for the engineering of automation systems
}

\author{
I.Haq $^{\mathrm{a}}$, R.P.Monfared ${ }^{\mathrm{a}}{ }^{*}$, R.Harrison ${ }^{\mathrm{a}}$, L. Lee ${ }^{\mathrm{b}}$, A.A.West ${ }^{\mathrm{a}}$ \\ ${ }^{a}$ Automation research group, Wolfson school of mechanical and manufacturing \\ engineering, Loughborough University, Loughborough, Leicestershire LE11 3TU, UK \\ ${ }^{b}$ Control strategy, Global Sigma Program Leader, Manufacturing Engineering, \\ Powertrain Operation, Ford Motor Company Ltd, UK
}

\begin{abstract}
Pressure on the powertrain sector of automotive industry is mounting as market demand for higher variety and lower cost automation systems increases. To maintain the market competitiveness, design-to-market time for new products should be significantly shorter and considerable cost saving needs to be made during the design and manufacture of production facilities. Virtual construction and test of systems prior to build is now identified as crucial because engineering changes due to untested designs cannot be afforded any longer, and approved designs need to be reused more efficiently.

In this article, the authors report research collaboration between Loughborough University and Ford Motor Company, UK to improve the current business and engineering model used at the powertrain industry. The current problems are highlighted and corresponding industrial engineering requirements are specified. The existing end user and supply chain interaction models are captured and a new business and engineering interaction models are proposed to address the requirements. A set of engineering services required for the new interaction models is described and an evaluation approach to identify the impact of the new model on the current enterprises are explained. In addition, an overview given on the research findings on the predicted impacts on the current businesses based on a set of evaluation criteria.
\end{abstract}

Keywords: Automation system, Powertrain, process and simulation model, Engineering services

\section{Background}

According to a survey carried out in 2008 (SMART 2008), global automation market is worth around $£ 180$ billion with an average estimated growth of $7.8 \%$ annually (prior to the current economical downturn). Factory automation takes 38\% of this market and of which $£ 62$ billion is the size of the European market in automation systems for control and monitoring sectors. These typically include application design, simulation and modelling, manufacturing, installation and maintenance.

However, global automation industry is changing rapidly. The product lifecycles shrink but demands for product variety and complexity increase and therefore profit margins decline (Molina, Rodriguez et al. 2005). This industry is also facing the advent of globalisation. Businesses, manufacturing practices, organisational and information structures are changing rapidly. Companies are moving from traditional methods, where in-house development teams typically work at a single site, to completely outsourcing or using specialised designed teams working from multiple sites.

For rapid response to such ever changing market demands, the automotive industry is under pressure to shorten production lifecycle time, for example when introducing new engine models in a powertrain sector. The time taken by western automotive firms to design a new engine model, build production lines and commence mass production is typically about 42 months while Japanese firms take around 36 months (Harrison, West et al. 2001; Monfared, West et al. 2002; Haq, Harrison et al. 2007). Also it has been recognised in the automotive industry that 6 months delay for the launch of a new product such as motor vehicle or large subassemblies e.g. 
transmission units, will cause a reduction by one third of its profit margin (Lee, Harrison et al. 2007).

However, the existing state-of-the-art approaches to manufacturing automation systems are facing fundamental limitations and complexity to reconfiguration, integration with supplier chain systems and optimisation. Because of a traditional hard-coded deterministic approach to the logical control of most production automation systems, it is too rigid and inflexible to enable efficient configuration and robust operations (Harrison and Colombo 2005), which is in particular important when existing plant is being upgraded or a new production system is being installed.

Therefore, the migration from today's control and management strategies to more flexible, intelligent manufacturing systems is one of the most difficult tasks facing this industry today. It is envisaged that a more proactive engineering approach and life cycle support to automation systems is required to facilitate highly flexible and agile manufacturing systems capable of providing easier and configurable design, installation, commission, and maintenance (Harrison, West et al. 2006).

This article summarises ongoing research efforts on development of a new approach to the Powertrain sector of western automotive industry in particular Ford Motor Company, UK. The research team in Loughborough University, in close collaboration with Ford Motor Company as major European automotive manufacturer and its leading automation machine/component builders (e.g. Krause, Schneider Electric, Bosch Rexroth), is investigating a solution for improving the current engineering approach to design and development of powertrain programs.

\section{Problems facing powertrain sector}

According to the European Automobile Manufacturers Association (ACEA), Europe is the largest vehicle producer in the world with over 13 major automobile manufacturers, contributing significantly in the EU economy (ACEA 2008). Ford Motor Company is one of the world's largest manufacturers of its kind with taking around 15\% of the European car market (Bekker 2009). Ford involves with globally distributed suppliers for their automation systems design and development i.e. Powertrain Systems. With ever growing emphasis being placed on global production systems, service and lifecycle support has become an integral part of the manufacturing system.

However, similar to the other leading players in automotive industry to maintain competitiveness, Ford is also facing extreme pressure to provide more agile engineering system to enable rapid response to the market changes. Despite the extreme expertise available in this industry, the engineering systems are fragmented and typically result in delays in production launch and therefore extending the rampup time (i.e. time to make and prepare production line as fast as per schedule to run different products). The notion of modular and reusability of design and manufacturing is not new in this industry, nonetheless, the infrastructure required to enable reuse of the past production knowledge is still not in place. Furthermore, it is a common understanding that ability to rapidly reconfigure previous designs (e.g. customisation) must be embedded into the engineering lifecycle, however application of various engineering tools used by hundreds of suppliers, make it almost impossible for the end user (i.e. Ford in this research) to provide a consistent control over the engineering development lifecycle. Throughout the lifecycle of automation system, there is no common representation/visualisation of engineering activities, between supply chain partners. 
To demonstrate the magnitude of the above mentioned problems, which typically leads to delays in launch of a new product or shutting down the production line, it suffices to mention that according to statistics captured by this research work, $50 \%$ saving in the ramp-up time would typically save 20 million Euros in a typical European production line, and every minute delay/malfunctioning in production line cost up to 6000 Euros for the end users (Harrison and Colombo 2005).

\section{Current approach to the engineering of powertrain automation}

In a typical powertrain program, a new engine project starts with strategic planning and market study, which leads to the identification of the product specification and the requirements, volumes, and fund approval. Following several simultaneous engineering meetings with suppliers and machine builders, the machine production lines are conceptually designed and manufacturing of lines is started at the machine builders' sites.

The machine builders carry out the detailed design, test and installation of machines, with frequent inspections by engineers from the engine manufacturers. Machine builders also sub-contract machine components to specialist component builders and concentrate on overall line design, line assembly and commissioning of the mechanical, electrical, hydraulic, and control systems. Typically about 4 months prior to the completion of the project, the machinery should be dismantled and delivered to the manufacturer sites for final tests and try-out machining. Onsite engineers then perform a detailed examination of all production and assembly lines at the site. At the end of this stage (known as job 1) engine manufacturer is ready to produce the first engine and commence the mass production. At the same time, the assembly lines are ready to assemble various engine components to the engine block. The lines will be under constant inspection for several months to avoid problems related to the training, machine adjustments and maintenance.

Conventionally the design activities by machine builders take place sequentially beginning with mechanical engineering followed by electrical, hydraulic and control engineering activities, as illustrated in figure 1. In the existing approach, the product specifications are typically interpreted by process engineers to produce a suitable machine configuration with process cycle charts written to specify the necessary timing of machine movements, which are later interpreted by programers to produce structured control software. Associated operator interface screens and machine diagnostics and monitoring applications are finally added (Harrison, West et al. 2001; Harrison, West et al. 2006). As a result, the design activities of hardware and control system remain isolated from one another and their verification can only be carried out during commissioning after build, which ultimately causes a longer and more costly ramp-up period. 


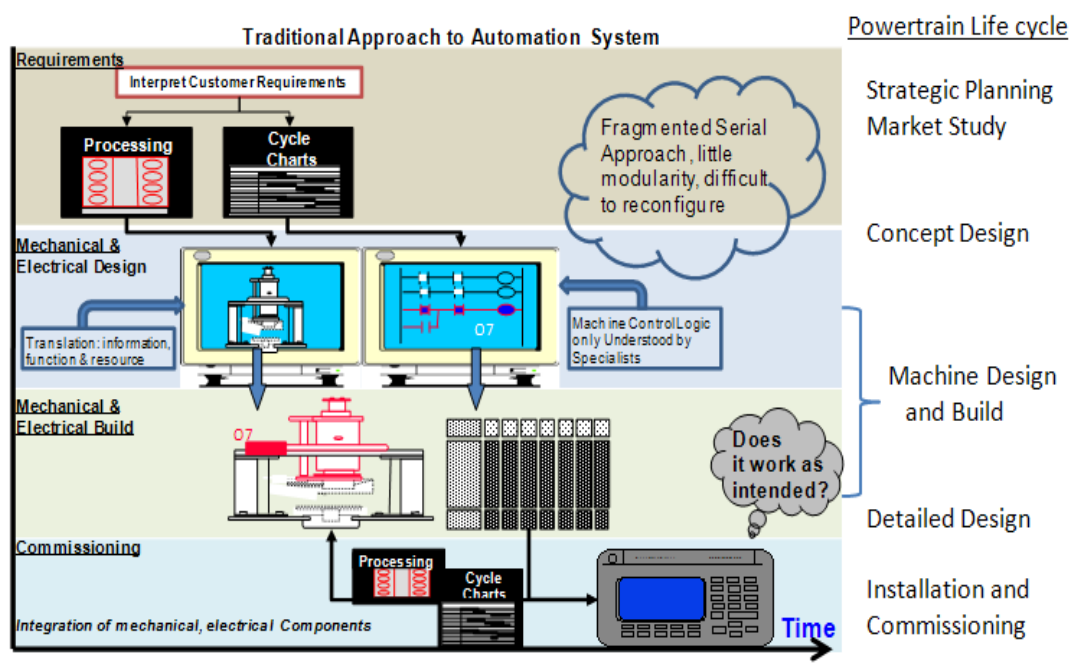

Figure 1: A convectional sequential approach to the development of automation systems

Despite the significant developments in the domain of assembly system design there is still a lack of well developed assembly system engineering techniques and methodologies, also highlighted by different research works (Harrison, West et al. 2001; Harrison, Lee et al. 2004; Harrison, West et al. 2006), for example: the existing state-of-the-art automation systems are relatively effective but approach to design and build process is almost entirely sequential and heavily segmented organisationally into different engineering disciplines.

This approach also has cost /quality impact later in the production phase of the machines lifecycle. For example if a change is required after several months of operation the engineers involved will be required to revise a large / if not all of the process in order to identify and limit the impact of the change on the machine.

Furthermore, end-user involves with a number of suppliers, and therefore dealing with inconsistent document formatting and structures. It has been observed that translations to the end user required format has been a root of many problems since there are (i) no common system representation, (ii) ad-hoc integration of engineering partners using fragmented design tools, (iii) the machine control logic is only understood by specialists and (iv) there is no modelling of machine operations.

More comprehensive description of the existing system is documented in (Monfared, West et al. 2002; Haq 2009).

\section{Next-generation of automation design and build}

The present global and competitive environment poses formidable challenges to global manufacturers including the automotive industry. To facilitate and accommodate unforeseen business changes within the automotive industry, a new proactive approach is required to design, build, assemble and reconfigure automation systems. Such innovative approach would require promoting new technologies and engineering methods to: a) enable engineering concurrency, b) investigate design alternatives prior to building and testing physical systems, c) provide predefined and pretested design components (as well as physical components), and d) enable application of virtual engineering at early stage of program design phases. Furthermore, such technologies and methods needs to be sufficiently end user oriented to allow them as major investor on the systems to own the engineering 
knowledge and be able to reuse the business and engineering knowledge for the future programs.

The lifecycle view of automation system design and development is highlighted in figure 2 on the left hand side and the existing approach to automation system design, its implementation, build and validation, is shown in the upper right side of the figure. The sequential nature of the detailed engineering design of automation systems provides little chance of concurrent engineering processes in order to shorten the life cycle. Performing test and verification processes at the end of the design phase presents risk of very costly rework on design and build. Moreover, lack of a repository system to store and reuse design mechanisms and manufacturing process modules (known as bill of processes) causes inefficient reuse of engineering knowledge collected from previous engineering programs.

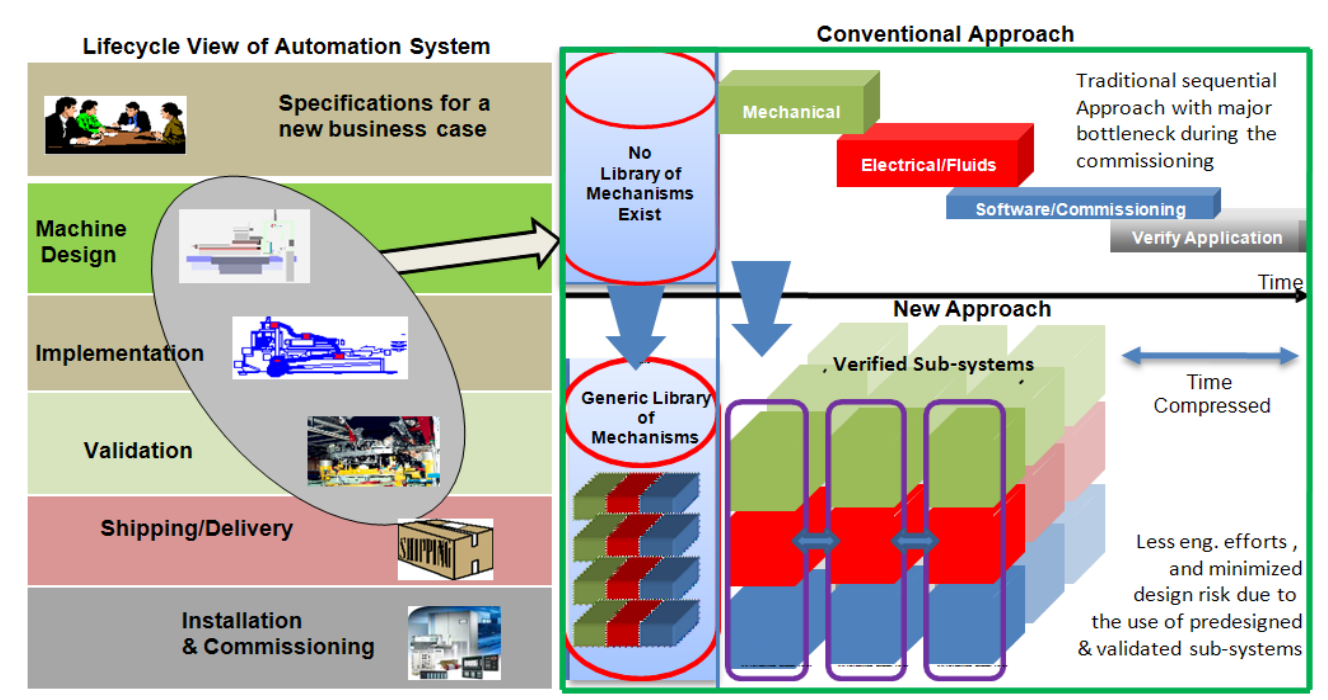

Figure 2: proposed component based approach to the development of automation systems

A new modular approach proposed for the design and build of automation system is also illustrated in figure 2. The vision is to decompose automation systems into standalone sub-systems and components in a generic manner, which are configurable with a set of parameters and may vary based on specific applications. The components include complete design for mechanic, electric, hydraulic, and control aspects, and are commissioned fully in respect with the functionality defined for the component. Such predesigned and pretested components (or a combination of some components and sub-systems) are to be stored in a library of reusable mechanisms. In this approach the concurrency of design can be significantly improved, leading to compression of program life cycle, with much reduced risk of design related malfunctioning due to the use of pretested systems modules. Nevertheless, the proposed approach to the design demands a set of advance engineering services such as comprehensive virtual engineering tools (to develop and then deploy the library of mechanisms), a consistent approach to the system design format across all supply chains, and a new business and engineering interaction model.

\section{Next generation collaborative and configurable automation systems (NGCCAS)}

A new generation of collaborative and configurable automation system is proposed as illustrated in figure 3. The principle concept behind the new approach is to provide primarily (re)configuration, collaboration and visualisation support for the complete 
lifecycle of the automation systems. This new realisation approach describes a systematic way to design and construct new automation system based on a more integrated, concurrent and vendor independent engineering environment.

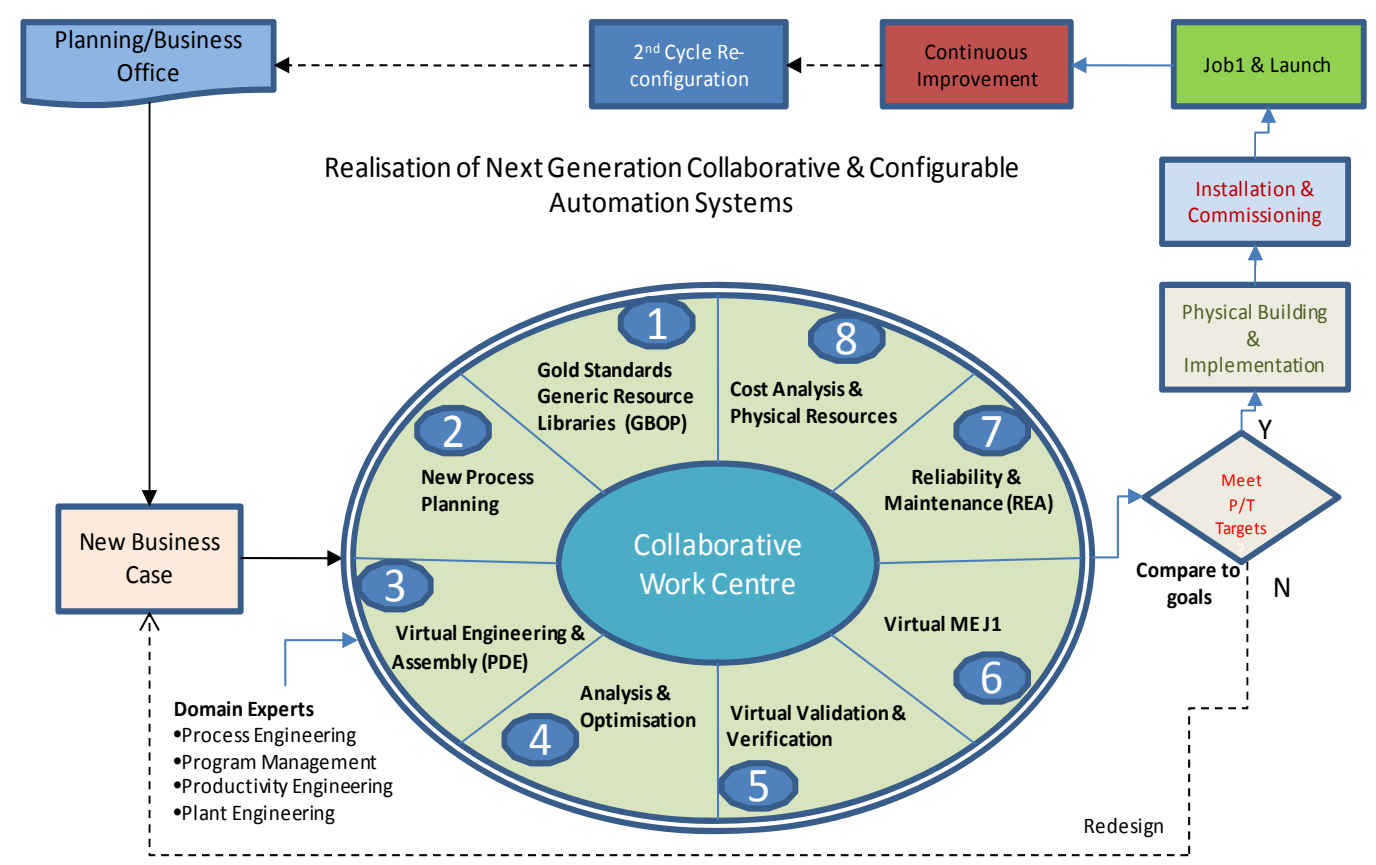

Figure 3: Proposed next generation collaborative and configurable automation

As illustrated, a new collaborative work centre (CWC) is proposed within the existing business processes. The proposed CWC will interact with the business and planning phase and manage design and build of new business cases (e.g. a new engine) in a virtual environment (prior to the physical build). The product of the CWC will be a set of predefined and validated virtual design for the complete assembly or manufacturing lines related to the new engine program. The virtual design will then be sent to the machine builders for final detailed design, manufacture and installations within the factory site. The collaborative work centre of the NGCCAS approach proposes eight engineering services originating from the end-user requirements. Initially, it contains a standard library of reusable, predefined and pre-validated mechanisms, i.e. predefined system components and bill of processes (BOP) that is required to produce the components. Such library is expected to be developed and completed gradually as knowledge of more engine program is captured. Based on preliminary reconfiguration of generic mechanisms, end user planning teams can identify commonality of the new project in comparison to the past programs and develop new process plan for the reuse of the existing system components and also develop new components and sub-systems. This allows the program manager to make adequate planning at early phases of the program. After planning, new mechanisms will be virtually designed and built by the supply chain experts and integrated into the existing reused components. Following the virtual engineering, the mechanisms will be assembled with existing mechanisms available in the library to achieve component, sub-system or systems. Furthermore, as part of the detailed design phase, analysis and optimisation services will enable domain experts to optimise components, subsystems and systems level requirements in terms of their cycle time, kinematics, and their control behaviours of the kinematics. This is proposed to be provided through a simulation services within the machine design build phase (e.g. checking the 
components/system design integrity, conditions and interlocks, and cycle time). The validation process (i.e. pre-commissioning) starts at the fifth step of the CWC as illustrated. It is proposed that virtual engineering services are required to enable verification of assembled components (and their associated sub-systems) to verify fully the new developed system prior to the real implementation of physical system. At this stage, a set of engineering application capabilities are prescribed to provide the virtual engineering services. Having completed the sub-systems verification, the complete manufacturing and assembly lines should be virtually tested and commissioned. By completing this process a new "Virtual Design J1 (VD1)" milestone would be met. This new milestone is proposed to provide an approval by the end user to authorise development of the physical systems.

The proposed CWC also highlights need for engineering capabilities to develop remote maintenance infrastructure to allow machine and component builders to provide diagnostics, repair, and monitoring services for the end user during the installation and after production launch. In addition, the CWC proposes a model in parallel with the business model to constantly analyse (and predict) the program resources costs and time as it progresses.

In addition, the proposed business and engineering model described as NGCCAS approach potentially offers significant improvement to the management of the powertrain programs when a new variation of engine is introduced to an existing line (known as $2^{\text {nd }}$ cycle). This is mainly due to the reusability of the system components and re-configurability of systems based on the proposed engineering services.

The new engineering model described above is being implemented in real industrial case at Ford Motor Company, in the UK. In the remainder of this article a prediction on the implementation impact of the new engineering model is discussed.

\section{Evaluation of impacts on engineering processes}

In a close collaboration between Loughborough University and Ford UK, following many industrial visits and several brainstorming sessions, some of the more urgent user needs were realised as follows. The current ramp-up period and reconfiguration of powertrain assembly lines are too costly and too long. The scope of virtual engineering during different phases of automation system lifecycle is limited due to the application of general purpose engineering tools. There is a great difficulty in reuse of the knowledge from the past powertrain programs. There is no formalised way to predict the cost and effort required for engineering changes (both product and processes). Verification of design can only be completed after build and installation, and therefore they are very costly to change. There is no uniform engineering application available to the end user to monitor, control and at later projects reuse the knowledge generated by globally distributed supply chain partners involved with a powertrain program.

To experiment the application of NGCCAS within a real industrial environment, Ford Engineering centre at Dunton Technical Centre, Basildon and Dagenham Plant, in Essex, UK were targeted. It was envisaged that prior to any recommendations for change, it is necessary to understand the existing business and engineering processes and be able to propose new NGCCAS approach in a form compatible with the end user business processes.

Figure 4 illustrates the approach taken to capture the existing processes for a typical powertrain program for the end user and criteria defined to evaluate the required processes changes when proposed migration is deployed. 


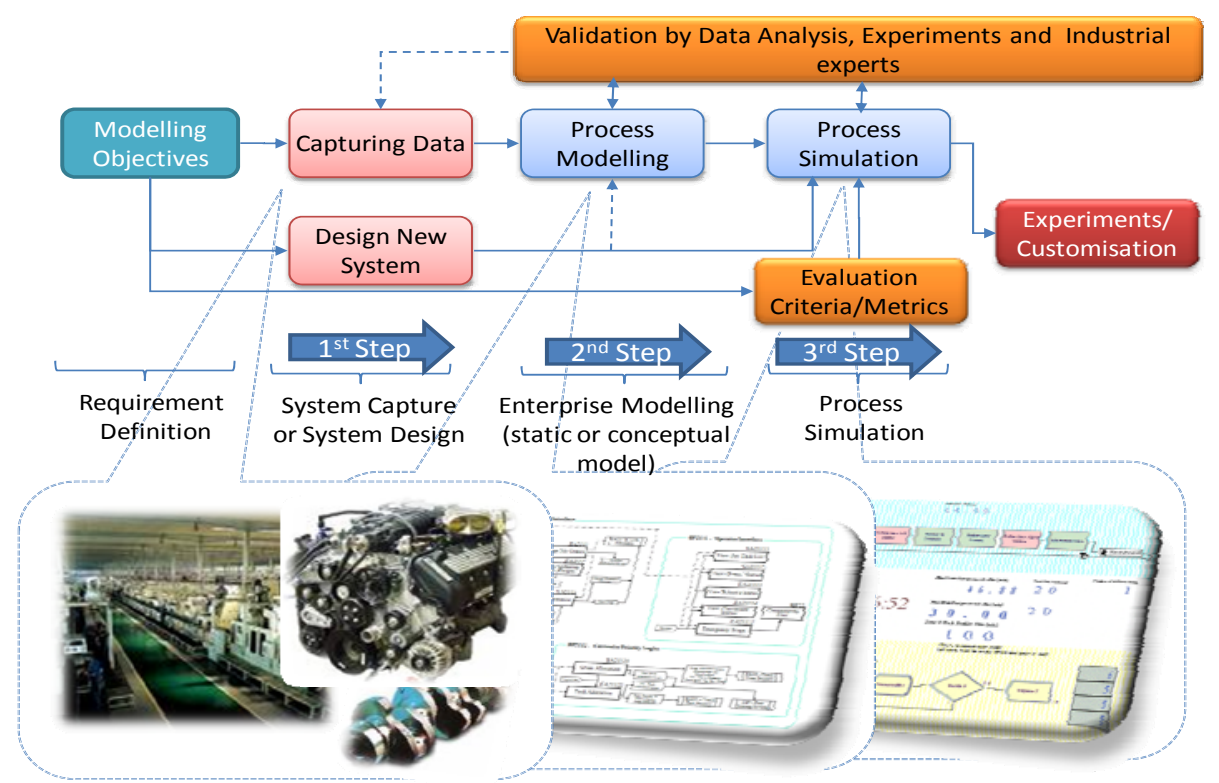

Figure 4: Enterprise modelling approach deployed in this research

As shown in the figure, definition of the end users' requirements constitutes the modelling objectives in this research. The aim is to understand and subsequently compare the two engineering models based on a set of criteria to enable prediction of the change impact on the existing engineering model. In general, Enterprise Modelling (EM) approach has been adopted in this research to capture and formalise system interactions. The aim of EM is not only to represent complex process structure of the corresponding organisation, but also to identify and propose possible improvements within systems. EM provides a solid foundation for the capturing, modelling and analyses of the business and engineering system. In this research, EM has been used in compliance with specifications defined by two international standards, namely ISO-19439 and ISO-15704 ${ }^{1}$. The existing processes were captured from the end user sites and formalised in form of a set of static diagrams developed in Loughborough University (Monfared, West et al. 2002) in compliance with the CIMOSA modelling architecture (ESPRIT 1993; Berio and Vernadat 1999; Mertins and Jochem 2005). The static models were used to develop process simulation models, as both models share similar modelling constructs (e.g. process decompositions, information and resource objects). The process simulation models facilitate customisation of models based on different variables captured from the physical environment. Both process models and process simulations have been undergone a vigorous validation process leading to the approvals from end users and supply chain engineers. In addition, other standard validation approaches were also deployed, such as those suggested by (Robinson and Bhatia 1995; Robinson 1997; Robinson 2006; Monfared, West et al. 2007). The NGCCAS approach continues by designing a new business and engineering processes and supply chain interactions. The proposed model is designed based on the end user requirements and engineering services required to meet those requirements. The new engineering model is also subjected to the process modelling, process simulation and validation steps.

\footnotetext{
${ }^{1}$ ISO 19439 - Enterprise Integration, Framework for Enterprise Modelling.

ISO 15704 - Industrial Automation Systems, Requirements for Enterprise - Reference Architectures and Methodologies.
} 
Completing the development of both business process and interaction models, the two models are compared on the basis of end user most important business performance metrics, e.g. cost, time and reliability of the design as engine program progresses. Finally, the process simulation models are customised and the modelling results are analysed based on the evaluation criteria, to provide predictions on the impact of introducing the new business model to the existing engineering systems.

\section{CASE STUDY}

Ford's DVM4 (Dagenham Plant, UK) engine assembly line, known as "Tiger assembly line" was considered as the case study in this research, as shown in figure 5.

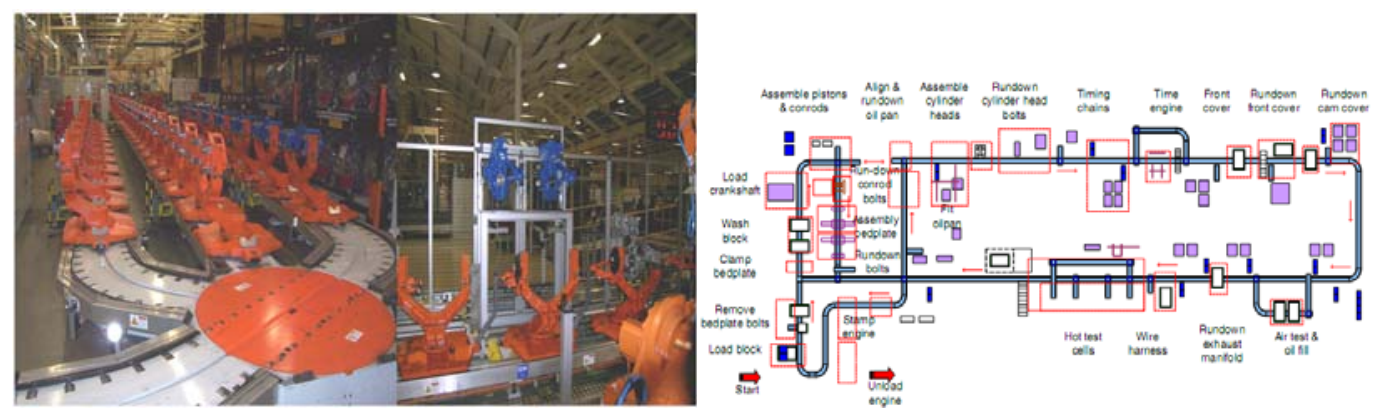

Figure 5: Tiger assembly line, Dagenham Plant, Ford, UK and a typical schematic for similar engine assembly line

Ford's engine production lines at this site are state-of-the-art industrial application to complex engine assembly operations. The lines typically include various combinations of production resources such as machines, conveyors, human operators. The introduction of a new engine project requires significant engineering competencies, time and budget. Multiple end user program teams are involved to coordinate thousand of parallel engineering activities with supply chain partners. This assembly line was installed and commissioned in 2007, with over $£ 130$ million investment for a capacity to produce over 500,000 mixed products per year (combination of various size diesel engines). Krause ${ }^{\mathrm{TM}}$ (a global automation machine builder) was mainly involved as a supply chain partner in the design and development of the Tiger assembly line including conveyors and work stations. The fully automated stations with robotic arms were supplied by the $\mathrm{ABB}^{\mathrm{TM}}$ suppliers (another global automation robot vendor). Figure 5 also shows a typical layout of an engine block assembly plant. Typical automation system consists of work stations and transport system i.e. conveyors that links together with various assembly stations. A conveyor carries pallets with loaded raw engine blocks which are then moved onto different workstations distributed along the transport system. At different workstations various engine parts are assemble e.g. pistons, connecting rods, cylinder head etc to raw engine block. Sensors and mechanical stops are used throughout the transport system to track the pallets and direct them down to different conveyors according to information stored in each respective pallet

The expected working life of this assembly line is about 7 to 10 years. However, in today's very competitive and turbulent automotive industry, any assembly line with such long life is required to produce many different engine variations. Therefore robust and less costly re-configurable automation systems are prerequisite. 


\section{Process Modelling}

As discussed earlier, the process model is represented in form of a set of diagrams as enhanced CIMOSA representation view (Monfared, West et al. 2002). According to this approach, system processes are decomposed into Domain Processes (DP), Business Processes (BP), and Enterprise Activities. Depending on the granularity of a model, a system can be broken down into various combinations of these modelling constructs. The models are represented in form of 5 different interlinking diagrams formalising context, structure, interaction, activity, and process definitions.

The current business and engineering processes are captured and formalised in the manner described above. Figure 6 illustrates a sample of the extensive engine program model developed in this research.

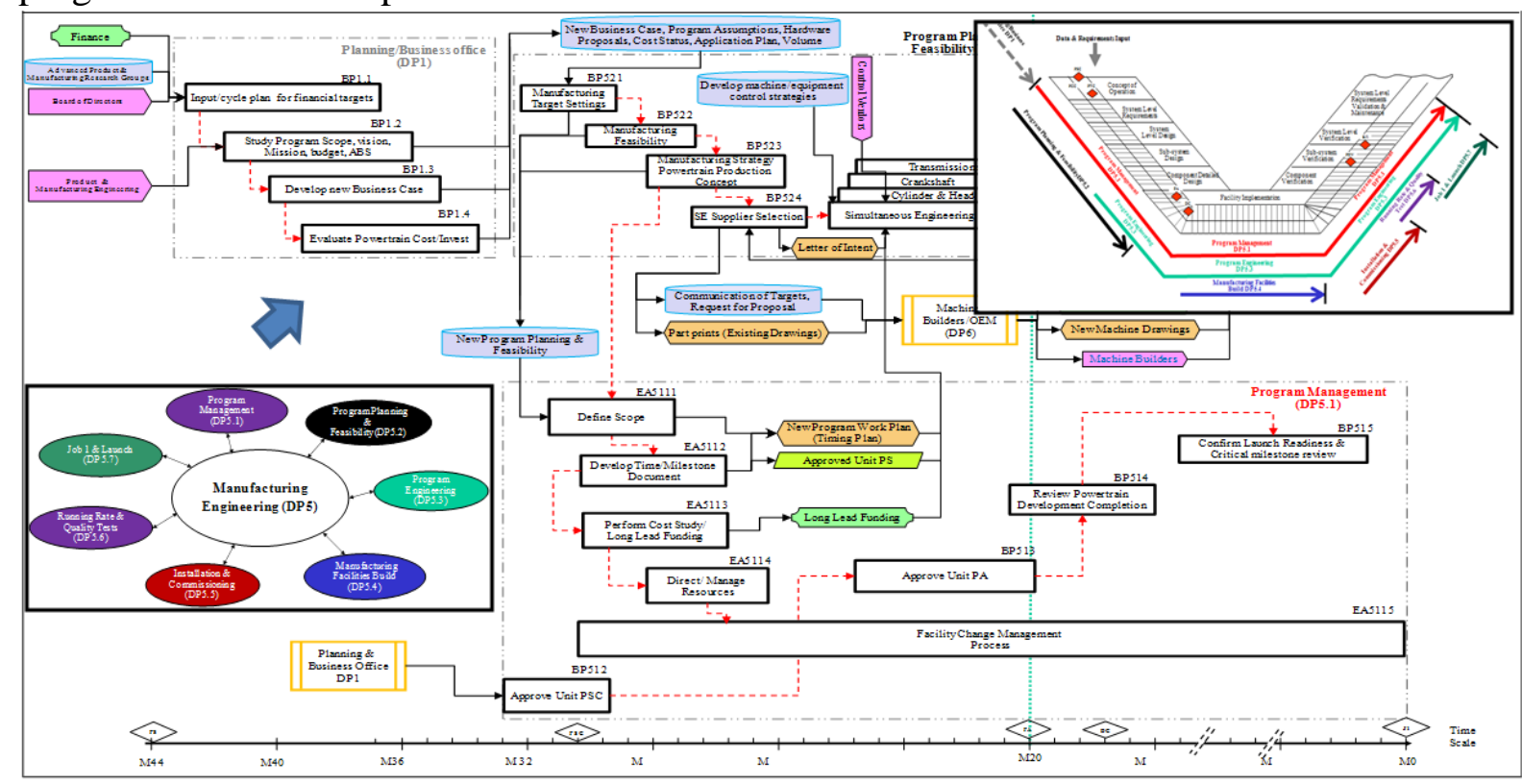

Figure 6: Part of the process and interaction models developed for the current powertrain engineering system

The process model is developed from the end-user perspective in which "planning and business office (DP1)" and "manufacturing engineering (DP5)” domains are responsible to design and build new automation systems from program start to its completion. The "DP5" is further decomposed systematically into seven sub domains as highlighted in figure 6. A new business case is developed by DP1to meet future business trends, which ultimately become input to sub domains of "DP5". This includes "program management (DP5.1)" and "program planning and feasibility (DP5.2)" as shown. Based on a new business case "DP5.2" develops a comprehensive document on "new program planning and feasibility" and delivers to the "DP5.1". In parallel "DP5.2" start communication with different suppliers. In response machine builders proposed their new ideas and cost models. Finally letter of intent is issued to the selected supplier.

Program Management (DP5.1) starts when new business case is initiated by DP1and finishes after completion of Job1 and launch period. Initially an important document called "new program work plan" and "long lead funding" is developed and delivered by "DP5.1" to business process "Simultaneous Engineering (SE) BP525" as highlighted in figure 6. Based on these documents end-user negotiates on time and cost for new program with machine builders. During SE process detail level of understanding is developed to identify system and sub-system level requirements. 
After detailed negotiations between end-user, machine builder and control vendors program is approved by board of directors and "First Order" is placed by the end-user to machine builder.

Once first order is placed, machine builders start design and build of new assembly machines. At the same time domain process "program engineering (DP5.3)" start preliminary activities for mass production. Typically new machines are delivered to the end-user in 12 to 18 months time period. During this time these new machines are partially commissioned and verified by end-user witness teams in process called " 1 st run-off and tryout phase (BP542)" at the vendor's site. Finally all newly built machines are shipped to the end-user to start domain process "installation and commissioning DP5.5”. In this domain the machine builders contribute with highly skilled commissioning teams to prepare new machines for a vital domain called "Running Rate and Quality Test (DP5.6)". The last domain of new program is started known as "job1 and launch (DP5.7)". The main focus of this domain is to achieve rate of climb (ROC) i.e. to run the line at its designed capability rate. Once ROC is confirmed program management (DP5.1) publish a completion report in the business process "lesson learned (BP572)" and confirm launch readiness for the vehicle plant.

\section{Process Simulation}

Process simulation modelling is used to measure and analyse performance of static process models. The process simulation also allows customisation of the process model based on the operational parameters. The simulation model analyse the process model over a period of typical powertrain program and measures key performance factors and allow execution of "what if scenarios". Figure 7 illustrates part of developed process simulation within this research. In developing the process simulation the prime focus was to maintain complete consistency between static process modelling and simulation model in order to seamlessly integrate the key modelling constructs between the two models. As one of the essential features within the process models used in this research is a hierarchical support structure and reusability of modelling constructs used to develop process models. Similarly, the process simulation models (developed using Arena ${ }^{\mathrm{TM}}$ commercial software (Seppanen and Kumar 2002; Bapat and Sturrock 2003)) were designed in several levels (i.e. submodels) as highlighted in figure 7, which correspond to the hierarchical structure and allow re-usability of modelling modules. To design, build and execute simulation models based on enterprise knowledge captured for process modelling, the simulation models are categorised into: a) functional objects, and b) behavioural objects. Functional objects are either inputs or outputs for each process, which may or may not dependent on other process functional objects (e.g. flow of information, physical resources etc.). On the other hand behavioural objects describe the logic or sequence of processes i.e. to define process logically either to make sequential or concurrent flows. To utilise these objects within the process simulation environment, simulation parameters (i.e. execution variables modules) were used to facilitate populating and configuring the process simulation models for specific powertrain program. In order to facilitate tracing and validation of simulation variable in such large and complex models, variables (e.g. information, event, time or human resource) are defined in a symbolic way to represent their concerned domain processes. For instance “INFO_BP435" or "PR_EA21" represent information or physical resource object for certain business process or enterprise activity. This approach also enables triggering simulation process based on preconditions, which correspond to the business and engineering processes of the powertrain program. Furthermore, such structured 
approach to the simulation design allows integration of the simulation models to (and from) other engineering applications, such as existing project management tools, and central data repository system.

As illustrated by figure 7 , the simulation process runs based on a set of default parameters suggested by the end user for typical (semi-generic) programs. The users vary parameters and execute the model. Following execution of a number of simulation replications, the modelling results are exported to external analysing tools to be compiled in a suitable format (e.g. reports, comparison graphs, etc.).

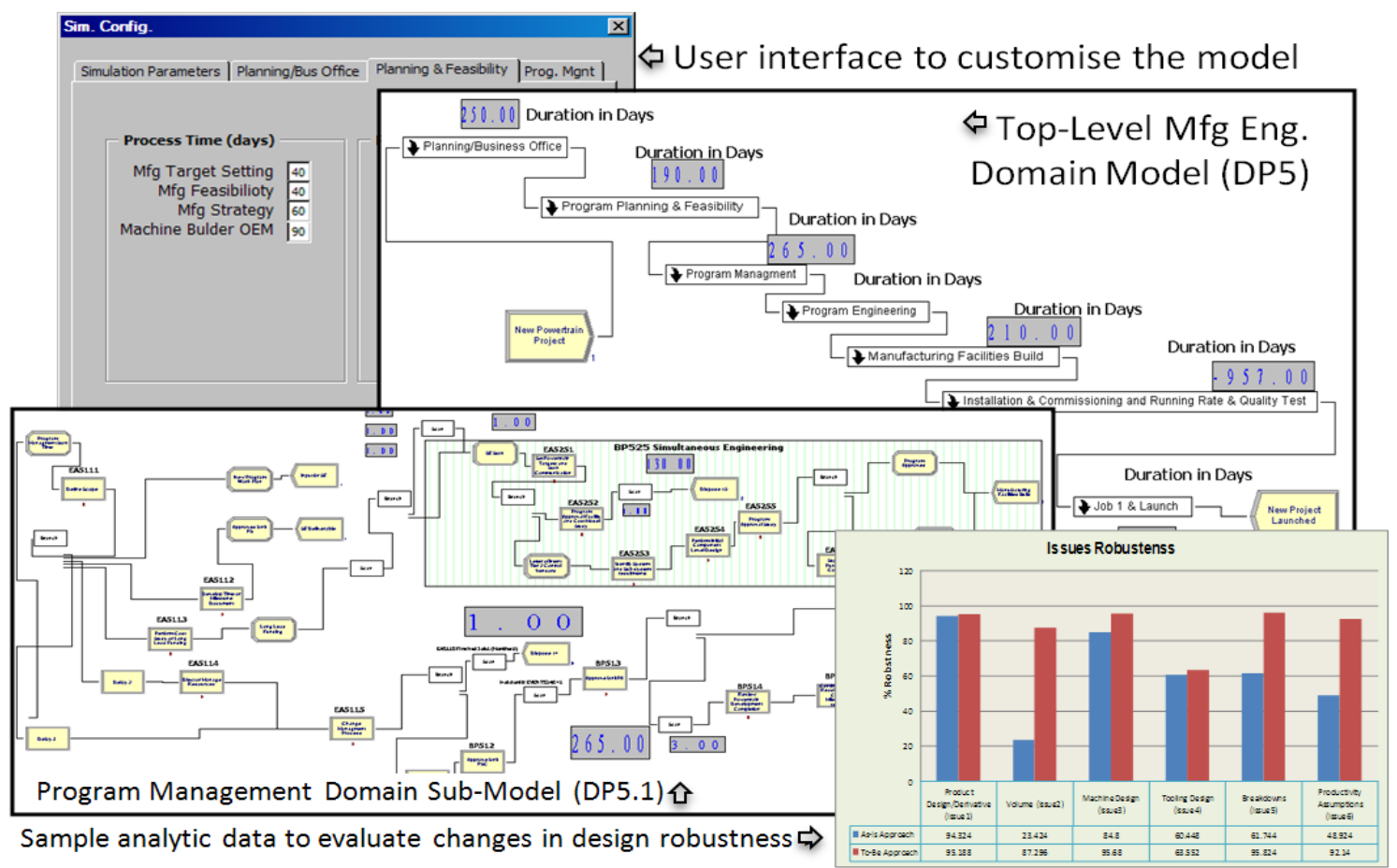

Figure 7: Snap shots of the developed simulation and analysis models

\section{New engineering process and interaction models}

Innovative engineering and interaction models are proposed to address a number of user requirements identified at the earlier stage of this research. These include: development of design mechanisms libraries to facilitate reusability, introducing new engineering services to enable consistent virtual design across the end user (and supply chain) program life cycle, description for new supply chain interaction models to integrate the machine/component builders engineering efforts in line with the end user activities, and provide more concurrent design processes to shorten the overall program time.

Figure 8 illustrates part of the new engineering process model developed in this research. As partially appears in the figure, libraries of pretested components, bill of processes, and design mechanisms are available to the end user engineers at various phases of powertrain program. The required engineering services are interpreted into engineering application tools required at each stage of the engineering model. The proposed models identify in great details what application functionality (e.g. component builder or system viewer - see figure 8) is required for each business process (BP's) and what engineering expertise (with what skill level) should use the new engineering applications. The new model also specifies changes on the current process flow, information and resource requirements for each process. Furthermore, it introduces a set of interaction mechanisms with the supply chain (e.g. exchange of 
information, documents and the timing within the program life cycle) to outsource certain part of the design process without losing control over the program management or the knowledge ownership. Comparing the models illustrated by figures 6 and 8, it is clear that due to the application of virtual engineering, more engineering activities can be completed concurrently, which will result in compression of the program overall time. In addition, the new "Virtual Design 1" (VD1) program management milestone introduced in this research will represent the phase that theoretically the design of all processes and facilities are completed virtually and tested fully (up to $100 \%$ as libraries are gradually populated). For further detail on the proposed engineering model refer to (Haq 2009).

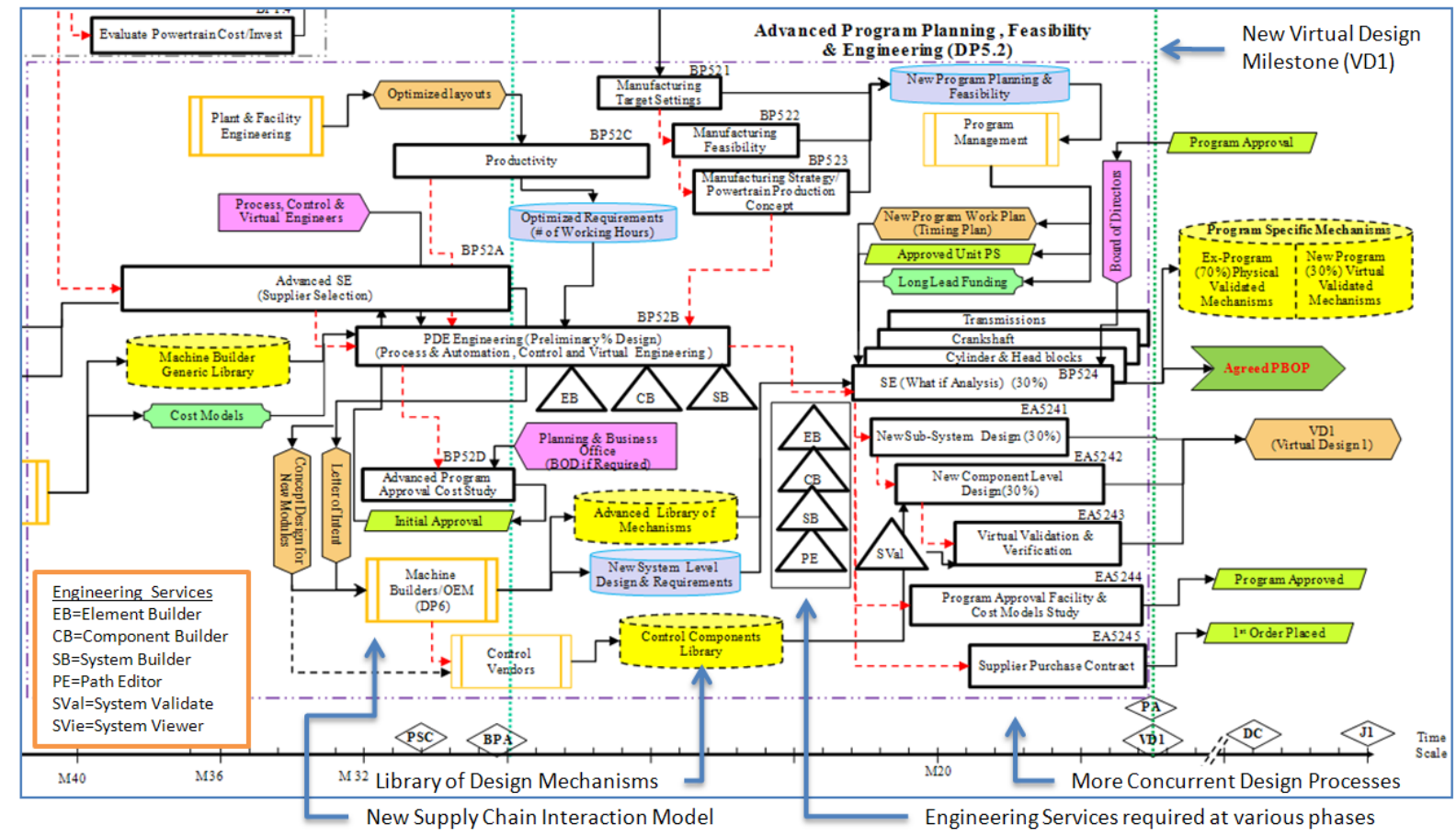

Figure 8: Part of the new business and engineering models proposed in this research

\section{Evaluation criteria}

After deploying the new business and engineering approach, to predict potential improvement on powertrain automation system, a number of evaluation criteria were identified based on the end user requirements. These criteria naturally include cost and time. In this research domain, the cost and time of the design and manufacturing processes and resources, and the cost of changes (due to errors, or design changes) are from outmost important factors. However, there are unquantifiable factors that also have significant impact on the program performance. For instance, the correctness of the design at each stage of the design of manufacturing and assembly lines have direct impact on the cost and time of engine program, as slight design misalignment at the early stages of the program life cycle, may lead to a major costly and timely re-design or re-build during the test and installation. In this research, an innovative method was developed to enable measuring and prediction of improvement on design correctness at each phase of the life cycle. The "robustness" factor was introduced as new evaluation criteria to compute (via simulation model) the potential improvement on the design correctness due to the application of pre-defined/pre-validated system component approach. A robustness ratio is calculated based on severity, frequency, and ability to eradicate a problem at a certain phase of the life cycle. The typical 
problems during the production launch are categorised into 6 different groups. Different robustness ratios are calculated for each domain processes based on the data captured and analysed from the end users. For example, it is unlikely to reach the nominal volume of engine production as originally scheduled. This is due to many reasons at different phases of the design and build. The calculation of probabilities shows that there is a $48 \%$ chance that nominal volume will not be met as scheduled because of the design problems during the "Program Planning and Feasibility" domain (DP5.2). Each DP has its own impact on each problem, and complex combinations of these ratios provide a metric to measure improvement on the design robustness, which in turn has direct impact on the cost.

\section{Predicted Results}

The developed process models of the powertrain program highlighted problems areas in the current business and engineering processes. The findings include lack of infrastructure and application tools to enable reusability of knowledge (e.g. design and processes) and lack of ability for rapid reconfiguration of design after process/product changes or following a $2^{\text {nd }}$ cycle production plan (i.e. introducing new product to the production line). These are represented in the process models as lengthy and expensive business processes, and also as major delays on production launch. It was also realised that many of the process bottlenecks identified by the developed models correspond with the initial business requirements set stated by the end users. This fact not only validates the reliability of the modelling approach, but also highlights that end users understand their current engineering problems as a whole, however they have difficulties in pinpointing the problems within the context of their engineering life cycle and therefore unable to rectify them.

The new business and engineering process model prescribes an enhanced approach for managing powertrain programs, which is predicted to improve some of the current problems. This should be possible though integration of proposed new engineering services (and their application tools - see figure 3), and revised supply chain interaction models suggested by this research. In addition, development of prevalidated design modules and the library of reusable modules have key importance on the business process improvement.

The process simulation models led to an extremely detailed calculation and comparison of system specifications before and after implementing the new business model. The modelling outcomes indicate very promising results in terms of saving in engineering costs, shortening the processes, and improving the reliability of the design of production lines (via calculation of the design robustness). For instance ${ }^{2}$, some of the areas that is predicted to be influenced heavily by the proposed approach are "Program Planning and Feasibility- DP5.2", "Program Engineering - DP5.2", and "Job1 and Launch - DP5.7". The modelling results predict 51\% reductions on the length of DP5.2, and 63\% on DP5.3. Similarly, the process DP5.7 is expected to initiate 5 months earlier than current approach (in a 42 month program). Regarding the use of engineering resource, a 61\% reduction in "Process and Automation Engineering" time during the DP5.3 is estimated, however, an increase in "Virtual Engineering" efforts by 3 times is predicted. Furthermore, the mathematical calculations suggest significant improvement in overall design robustness. For instance, the robustness ratio in DP5.2 and DP5.7 is expected to increase from 52\%

\footnotetext{
2 Further information on the modelling approach and complete modelling and predicted results are documented by Haq (Haq 2009).
} 
and $60 \%$ to $92 \%$ and $96 \%$. This is a significant improvement on the design process, which has direct impact on time and cost of the programs by avoiding reworks and changes.

However, to understand fully the impact of the proposed next generation collaborative and configurable automation systems (NGCCAS), the new approach should be implemented within an industrial environment. Preparation is being made to implement the NGCCAS approach within the Ford engineering centre during its next major engine program in the UK. Initially, the new engineering model will be used in parallel with the program management system to shadow the processes. This will enable a direct comparison of predicted results with actual benefits of utilisation of engineering tools in real engineering processes.

\section{CONCLUSIONS}

Lack of agility and responsiveness to the market changes were identified as some of the existing problems with automation industry. An approach to the next generation collaborative and configurable automation systems (NGCCAS) was proposed to improve the current problems in the design and build of powertrain automation systems. The developed approach proposes establishes link between business requirements and engineering applications. It provides changes on the business and engineering processes within this sector of industry, and describes new supply chain interaction mechanism. The existing enterprise processes were captured and compared with a new model of the engineering paradigm. The comparison indicates considerable improvement in the way current automation programs work. A set of engineering services combined as a collaborative work centre (CWC) was defined to be integrated in the current business and engineering model. Description for the corresponding engineering applications and their potential implementation phase within the engineering life cycle were briefly discussed. The use of enterprise modelling and process simulations was discussed to visualise the current and the future enterprise processes, and enable detail analyses of various production scenarios.

On the basis of the modelling approach taken, it was predicted that the application of NGCCAS approach should enhance significantly the agility and responsiveness of automation system development. The new engineering model is planned to be tested in a real industrial environment as part of collaboration between research group in Loughborough University and Ford Motor Company, UK,

Acknowledgment

The authors gratefully acknowledge the support from Innovative Manufacturing and Construction Research Centre (IMCRC) as part of the Business Driven Automation Project.

\section{Table of Figures}

Figure 1: A convectional sequential approach to the development of automation systems Figure 2: proposed component based approach to the development of automation systems Figure 3: Proposed next generation collaborative and configurable automation

Figure 4: Enterprise modelling approach deployed in this research

Figure 5: Tiger assembly line, Dagenham Plant, Ford, UK and a typical schematic for similar engine assembly line 
Figure 6: Part of the process and interaction models developed for the current powertrain engineering system

Figure 7: Snap shots of the developed simulation and analysis models

Figure 8: Part of the new business and engineering models proposed in this research

\section{References}

ACEA. (2008). "The engine of Europe." European Automobile Manufacturers' Assocoation, from http://www.acea.be/index.php/news/news_detail/the_engine_of_europe/.

Bapat, V. and D. T. Sturrock (2003). The Arena Product Family: Enterprise Modelling Solutions. Proceedings of the 35th conference on Winter simulation: driving innovation New Orleans, Louisiana Winter Simulation Conference

Bekker, H. (2009). "Best-Selling Car Manufacturers in Europe in 2008." International trade, from http://internationaltrade.suite101.com/article.cfm/bestselling_car_manufacture rs_in_europe_in_2008.

Berio, G. and F. B. Vernadat (1999). "New developments in enterprise modelling using CIMOSA." Computers in Industry 40: 99-114.

ESPRIT, C. A. (1993). CIMOSA: open system architecture for CIM, Springer-Verlag, Berlin.

Haq, I. U. (2009). Development of Next Generation Configurable and Collaborative Approach for Automation Systems Wolfson School of Mechancial and Manufacturing Engineering. Loughborough, Loughborough University. PhD.

Haq, I. U., R. Harrison, et al. (2007). Lifecycle Framework for Modular Configurable Automation Systems. Fourth IFAC Conference on Management \& Control of Production \& Logistics. Romania.

Harrison, R. and A. W. Colombo (2005). Collaborative Automation From Rigid Coupling Towards Dynamic Reconfigurable Production Systems. $16^{\text {th }}$ IFAC World Control Congress, Prague.

Harrison, R., S. M. Lee, et al. (2004). Lifecycle engineering of modular automated machines. Industrial Informatics, 2004. INDIN '04. 2004 2nd IEEE International Conference on.

Harrison, R., A. West, et al. (2001). "Distributed engineering of manufacturing machines." Proceedings of the Institution of Mechanical Engineers, Part B: Journal of Engineering Manufacture 215(2): 217-231.

Harrison, R., A. A. West, et al. (2006). Lifecycle Engineering of Future Automation Systems in the Automotive Powertrain Sector. Industrial Informatics, 2006 IEEE International Conference on.

Lee, S., R. Harrison, et al. (2007). "A component-based approach to the design and implementation of assembly automation system." Proceedings of the Institution of Mechanical Engineers, Part B: Journal of Engineering Manufacture 221(5): 763-773.

Mertins, K. and R. Jochem (2005). "Architectures, methods and tools for enterprise engineering." International Journal of Production Economics 98(2): 179-188. 
Molina, A., C. Rodriguez, et al. (2005). "Next-generation manufacturing systems: key research issues in developing and integrating reconfigurable and intelligent machines." International Journal of Computer Integrated Manufacturing 18: 525-536.

Monfared, R., A. West, et al. (2002). "An implementation of the business process modelling approach in the automotive industry." Proceedings of the Institution of Mechanical Engineers, Part B: Journal of Engineering Manufacture 216(11): 1413-1427.

Monfared, R. P., A. A. West, et al. (2007). "Evaluating a new Flexible Soldering System for Electronics SMEs." Proceedings of the Institution of Mechanical Engineers, Part B: Journal of Engineering Manufacture 222, Number 2 / 2008 (Part B): 273-283.

Robinson, S. (1997). "Simulation model verification and validation: increasing the users' confidence." Proceeding of the 1997 winter simulation conference: 5359.

Robinson, S. (2006). "Conceptual modeling for simulation: issues and research requirements." Proceedings of the 2006 winter simulation conference: 792800.

Robinson, S. and V. Bhatia (1995). "Secrets of successful simulation projects." Proceeding of the 1995 winter simulation conference: 61-67.

Seppanen, M. S. and S. Kumar (2002). Using simulation to teach business processes design and improvement. Proceedings of the 34th conference on Winter simulation: exploring new frontiers San Diego, California

SMART. ( 2008). "Monitoring and control: today’s market, its evolution till 2020 and the impact on ICT on these, European Commission, DG Information Society and Media." from http://www.decision.eu/smart2007.htm. 